\title{
Management of massive and nonmassive pulmonary embolism
}

Vishal Sekhri ${ }^{1}$, Nimeshkumar Mehta ${ }^{1}$, Naveen Rawat ${ }^{1}$, Stuart G. Lehrman ${ }^{1}$, Wilbert S. Aronow ${ }^{1,2}$

1Divisions of Pulmonary, Critical Care and Sleep Medicine, Department of Medicine, New York Medical College, Valhalla, NY, USA

2Department of Cardiology, New York Medical College, Valhalla, NY, USA

Submitted: 5 April 2012

Accepted: 20 April 2012

Arch Med Sci 2012; 8, 6: 957-969

DOI: 10.5114/aoms.2012.32402

Copyright $\odot 2012$ Termedia \& Banach

\section{Corresponding author:} Wilbert S. Aronow MD Cardiology Division New York Medical College Macy Pavilion, Room 138 Valhalla, NY 10595, USA Phone: (914) 493-5311

Fax: (914) 235-6274

E-mail: wsaronow@aol.com

\begin{abstract}
Massive pulmonary embolism (PE) is characterized by systemic hypotension (defined as a systolic arterial pressure $<90 \mathrm{~mm} \mathrm{Hg}$ or a drop in systolic arterial pressure of at least $40 \mathrm{~mm} \mathrm{Hg}$ for at least 15 min which is not caused by new onset arrhythmias) or shock (manifested by evidence of tissue hypoperfusion and hypoxia, including an altered level of consciousness, oliguria, or cool, clammy extremities). Massive pulmonary embolism has a high mortality rate despite advances in diagnosis and therapy. A subgroup of patients with nonmassive PE who are hemodynamically stable but with right ventricular (RV) dysfunction or hypokinesis confirmed by echocardiography is classified as submassive PE. Their prognosis is different from that of others with non-massive PE and normal RV function. This article attempts to review the evidence-based risk stratification, diagnosis, initial stabilization, and management of massive and nonmassive pulmonary embolism.
\end{abstract}

Key words: pulmonary embolism, anticoagulation, thrombolysis, embolectomy.

\section{Introduction}

Massive pulmonary embolism (PE) has a high mortality rate despite advances in diagnosis and therapy. Pulmonary embolism can be classified depending on degree of pulmonary vasculature obstructed by burden of blood clots. While classifying pulmonary embolism, it is reasonable to consider not only size of the embolus but also the underlying cardiopulmonary reserve. Therefore, the best way to classify pulmonary embolism depends on the hemodynamic consequences.

Massive PE is characterized by systemic hypotension (defined as a systolic arterial pressure $<90 \mathrm{~mm} \mathrm{Hg}$ or a drop in systolic arterial pressure of at least $40 \mathrm{~mm} \mathrm{Hg}$ for at least 15 min which is not caused by new onset arrhythmias) or shock (manifested by evidence of tissue hypoperfusion and hypoxia, including an altered level of consciousness, oliguria, or cool, clammy extremities) [1, 2]. A subgroup of patients with nonmassive PE who are hemodynamically stable but with right ventricular (RV) dysfunction or hypokinesis confirmed by echocardiography is classified as submassive PE. Their prognosis is different from that of others with non-massive PE and normal RV function. 


\section{Risk stratification}

In patients with normal blood pressure and no signs of shock on presentation, RV dysfunction provides indirect evidence of severe pulmonary artery obstruction and impending hemodynamic failure. About $80 \%$ of patients with acute PE have normal systemic arterial pressure at the time of presentation [3], and between $27 \%$ and $56 \%$ of normotensive patients have echocardiographic evidence of RV dysfunction [3-6].

As per the International Cooperative Pulmonary Embolism Registry (ICOPER) [7], RV dysfunction was noted on echocardiography in $40 \%$ of 1,135 normotensive patients, and the presence of RV dysfunction was associated with a 2-fold increase in all-cause mortality during 3 months follow-up after diagnosis of acute PE. As per the Management Strategy and Prognosis of Pulmonary Embolism (MAPPET) registry [8], the in-hospital mortality according to the degree of hemodynamic compromise in 1001 patients with acute PE is shown in Table I. Table II shows the effect of RV dysfunction on in-hospital mortality in 3 other prospective studies [3-5].

Thus, the presence of RV dysfunction identifies normotensive patients with acute PE who have a significantly higher risk of recurrent $P E$ and death. In the spectrum of severity of PE, these normotensive patients with evidence of RV dysfunction are classified as submassive PE, and they are in the grey area between patients with normal blood pres-

Table I. In-hospital mortality according to the degree of hemodynamic compromise in 1001 patients with acute pulmonary embolism (adapted from [8])

\begin{tabular}{|lcc|}
\hline Variable & $n$ & Mortality \\
\hline $\begin{array}{l}\text { RV dysfunction, no arterial } \\
\text { hypotension }\end{array}$ & 407 & $8.1 \%$ \\
\hline Arterial hypotension $^{1}$ & 316 & $15.2 \%$ \\
\hline Cardiogenic shock $^{2}$ & 102 & $24.5 \%$ \\
\hline Cardiopulmonary resuscitation $^{-176}$ & 176 & $64.8 \%$ \\
\hline
\end{tabular}

${ }^{1}$ Arterial hypotension - systolic arterial pressure $<90 \mathrm{~mm} \mathrm{Hg}$ or drop in systolic pressure of at least $40 \mathrm{~mm} \mathrm{Hg}$ for $>15 \mathrm{~min}$ but no need for catecholamines except for dobutamine $\leq 5 \mathrm{mg} / \mathrm{kg} / \mathrm{min}$. ${ }^{2}$ Cardiogenic shock - arterial hypotension plus clinical signs of tissue hypoperfusion and hypoxia, including an altered level of consciousness, a urine output of $<30 \mathrm{ml} / \mathrm{h}$, or cold and clammy extremities. RV - right ventricular sure and normal or near-normal RV function (good prognosis) and those presenting with hypotension, shock, or cardiac arrest (grave prognosis). It is important to identify these patients with submassive PE as the role of fibrinolysis remains controversial in this set of patients [9].

\section{How to define right ventricular dysfunction by echocardiography}

The main criteria, used in the above mentioned studies to define RV dysfunction, are qualitative with mild, moderate, or severe RV hypokinesis and quantitative. Quantitative criteria include RV dilatation with a RV/LV end-diastolic diameter > 1, a RV end-diastolic diameter $>30 \mathrm{~mm}$, and paradoxical septal systolic motion, pulmonary hypertension with a pulmonary artery systolic pressure $>30 \mathrm{~mm} \mathrm{Hg}$ and a tricuspid regurgitant velocity $>2.8 \mathrm{~m} / \mathrm{s}$, and absence of RV wall hypertrophy (free wall thickness $>7 \mathrm{~mm}$ ).

McConnell et al. [10] reported a study which helped to differentiate RV dysfunction due to PE. This study showed a particular finding of akinesia of the RV free wall and sparing of the RV apex or normal motion of the RV apex in patients with known, large $P E$. This finding is referred as McConnell's sign For PE, McConnell's sign had a sensitivity of $77 \%$, specificity of $94 \%$, positive predictive value of $71 \%$, and negative predictive value of $96 \%$.

\section{Surrogate markers for right ventricular dysfunction}

Echocardiography may not be always readily available. Other abnormalities described as "surrogate markers" for RV dysfunction in the setting of acute PE include physical examination, electrocardiographic (ECG) findings, cardiac biomarkers, and chest computed tomography.

The physical findings associated with RV dysfunction are tachycardia, elevated jugular venous pressure, parasternal heave, loud P2, and tender enlarged liver. All of the above clinical findings are neither specific nor sensitive when used alone.

Despite its low sensitivity and specificity, the ECG adds diagnostic value in determining the extent of the clot burden and supporting the finding of RV dysfunction as seen by echocardiography

Table II. Effect of right ventricular dysfunction on in-hospital mortality in 3 prospective studies

\begin{tabular}{|lcccc|}
\hline Trial & $\begin{array}{c}\text { No. of normotensive } \\
\text { patients with acute PE }\end{array}$ & $\begin{array}{c}\text { Percentage of patients } \\
\text { with RV dysfunction }\end{array}$ & RV dysfunction & Normal RV function \\
\hline Grifoni et al. [3] & 162 & $31 \%$ & 4.6 & 0 \\
\hline Kasper et al. [4] & 317 & $27 \%$ & 12.6 & 0.9 \\
\hline Ribeiro et al. [5] & 126 & $56 \%$ & 12.9 & 0 \\
\hline PE- pulmonary embolism, RV - right ventricular
\end{tabular}


[11]. Sinus tachycardia, supraventricular tachyarrhythmias, the S1Q3T3 pattern, new complete or incomplete right bundle branch block, and p pulmonale are some of the ECG patterns described in association with pulmonary embolism [9, 12]. In the PIOPED database, $30 \%$ of patients were noted to have a normal ECG, but the most common ECG finding was noted to be non-specific abnormalities of the ST segment or T wave in $49 \%$ of their population [13]. Inverted T waves in leads V1-V4 may be present, especially in the setting of massive PE. In one study, this pattern was shown to correlate with the severity of PE [14].

The ECG scoring systems have also been designed and demonstrated to correlate with percentage perfusion defects on ventilation-perfusion lung scanning and severity of pulmonary hypertension from PE [15]. Daniel et al. [16] derived a 21-point ECG scoring system (shown in Table III) to determine the relationship between ECG score and systolic pulmonary arterial pressure (SPAP) in patients with and without PE. At a cutoff of 10 points, the sensitivity and specificity of this ECG score for the recognition of severe pulmonary hypertension (SPAP > $50 \mathrm{~mm} \mathrm{Hg}$ ) secondary to PE were $23.5 \%$ and $97.7 \%$, respectively.

About $30 \%$ to $40 \%$ of patients with PE have elevated serum cardiac troponin levels [17]. The likely explanation for troponin release in PE is the development of microinfarcts from abrupt increase in pulmonary artery pressure with an elevation in RV wall tension leading to increased RV oxygen demand and decreased perfusion of the right coronary artery, even in the absence of atherosclerotic disease [18]. Elevated troponin levels have also been shown to be a risk factor for poor outcome in acute $\mathrm{PE}$ and correlate significantly with electrocardiographic and echocardiographic parameters of RV pressure overload and dysfunction [19].

Elevated troponin levels (cTnl > $1.5 \mathrm{ng} / \mathrm{ml}$, cTnT $>0.1 \mathrm{ng} / \mathrm{ml}$ ) have been shown to be associated with the 2 major end points of overall mortality and complicated in-hospital course like need for inotropic support, an escalation of therapy with thrombolytics, cardiopulmonary resuscitation, and mechanical ventilation. The negative predictive value of troponin (cTnl $<0.07 \mathrm{ng} / \mathrm{ml}, \mathrm{cTnT}<0.04 \mathrm{ng} / \mathrm{ml}$ ) was $92 \%$ to $93 \%$ for predicting major clinical events and help to identify a group of patients at low risk in the acute setting [20].

Plasma pro-B-type natriuretic peptides (BNP), a plasma neurohormone released from the cardiac ventricles in response to increased pressure and stretch, has been shown to correlate with left ventricular dysfunction. RV dysfunction in patients with PE can also result in an elevation of serum BNP levels, and the magnitude of BNP elevation has been shown to predict adverse outcomes [20]. Several
Table III. ECG scoring method (adapted from [14])

\begin{tabular}{|c|c|}
\hline ECG findings & Score \\
\hline Sinus tachycardia (> 100 beats/min) & 2 \\
\hline Incomplete right bundle branch block* & 2 \\
\hline Complete right bundle branch block ${ }^{* *}$ & 3 \\
\hline T-wave inversion in leads V1 through V4 & 4 \\
\hline \multicolumn{2}{|l|}{ T-wave inversion in lead V1: } \\
\hline$\bullet<1 \mathrm{~mm}$ & 0 \\
\hline - $1-2 \mathrm{~mm}$ & 1 \\
\hline - $>2 \mathrm{~mm}$ & 2 \\
\hline \multicolumn{2}{|l|}{ T-wave inversion in lead V2: } \\
\hline$\bullet<1 \mathrm{~mm}$ & 1 \\
\hline - $1-2 \mathrm{~mm}$ & 2 \\
\hline - $>2 \mathrm{~mm}$ & 3 \\
\hline \multicolumn{2}{|l|}{ T-wave inversion in lead V3: } \\
\hline$\bullet<1 \mathrm{~mm}$ & 1 \\
\hline - $1-2 \mathrm{~mm}$ & 2 \\
\hline - > $2 \mathrm{~mm}$ & 3 \\
\hline S wave in lead $\mathrm{I}^{+}$ & 0 \\
\hline Q wave in lead $\mathrm{III}^{++}$ & 1 \\
\hline Inverted T wave in lead III & 1 \\
\hline S1Q3T3 present & 2 \\
\hline Total score & 21 \\
\hline
\end{tabular}

${ }^{*} Q R S$ complex of 0.10-0.11 s, $S$ wave in lead I and terminal $R$ wave in $V 1>1.5 \mathrm{~mm},{ }^{* *} Q R S>0.11 \mathrm{~s}$ and $S$ wave in lead I and terminal $R$ wave in $V 1>1.5 \mathrm{~mm}$. ${ }^{+}$First negative deflection after an $R$ wave $>1.5 \mathrm{~mm}$. ${ }^{++}$First negative deflection after the $P$ wave and before any $R$ wave $>1.5 \mathrm{~mm}$ )

different studies have been published to determine the cut off value of BNP or N terminal-proBNP (NTproBNP) for predicting the in-hospital course of normotensive patients with acute PE [21, 22]. In one study of 73 patients with acute PE, patients with a $B N P<90 \mathrm{pg} / \mathrm{ml}$ had a negative predictive value of $93 \%$ for major clinical events [21].

Kostrubiec et al. [23] showed that the combination of troponin and NT-proBNP is better for risk stratification of patients with PE in the acute setting. Results from this study are shown in Table IV. Incorporation of echocardiographic data did not improve group selection in this study.

The Heart-type fatty acid-binding protein H-FABP might be a useful biomarker for risk stratification of normotensive patients with acute PE [24, 25]. Dellas et al. conducted a study with 126 consecutive normotensive patients with confirmed PE and studied the role of H-FABP as a biomarker for risk stratification of patients with normotensive acute PE [25]. During the first 30 days, 9 (7\%) patients suffered complications. These patients had higher baseline $\mathrm{H}$-FABP values (median, $11.2 \mathrm{ng} / \mathrm{ml}$; interquartile 
Table IV. All-cause mortality in 100 normotensive patients with acute pulmonary embolism (adapted from [21])

\begin{tabular}{|lccc|}
\hline Variables & Total no. of patients & Deaths & Percentage \\
\hline NT-proBNP $<600 \mathrm{ng} / \mathrm{l}$ & 28 & 0 & $0 \%$ \\
\hline NT-proBNP $>600 \mathrm{ng} / \mathrm{l}$ and cTnT $<0.07 \mu \mathrm{g} / \mathrm{l}$ & 54 & 6 & $11 \%$ \\
\hline NT-proBNP $>600 \mathrm{ng} / \mathrm{l}$ and cTnT $>0.07 \mu \mathrm{g} / \mathrm{l}$ & 18 & 9 & $50 \%$ \\
\hline Total & 100 & 15 & $15 \%$ \\
\hline
\end{tabular}

Table V. Risk Scorefor 30 Day adverse events (adapted from [26])

\begin{tabular}{|c|c|c|}
\hline Prognostic factor & Categories & Points \\
\hline \multirow[t]{2}{*}{ Altered mental status } & No & 0 \\
\hline & Yes & 10 \\
\hline \multirow{2}{*}{$\begin{array}{l}\text { Cardiogenic shock } \\
\text { on admission }\end{array}$} & No & 0 \\
\hline & Yes & 6 \\
\hline \multirow[t]{2}{*}{ Cancer } & No & 0 \\
\hline & Yes & 6 \\
\hline \multirow[t]{5}{*}{ BNP [ng/l] } & $<100$ & 0 \\
\hline & $100-249$ & 1 \\
\hline & $250-499$ & 2 \\
\hline & $500-999$ & 4 \\
\hline & $>1000$ & 8 \\
\hline \multirow[t]{5}{*}{ RV/LV ratio } & $0.2-0.49$ & 0 \\
\hline & $0.5-0.74$ & 3 \\
\hline & $0.75-1.00$ & 5 \\
\hline & $1.00-1.25$ & 8 \\
\hline & $>1.25$ & 11 \\
\hline
\end{tabular}

Altered mental status was defined as disorientation, stupor or coma Range of total prognostic score 0-41. The points assigned correspond to the following risk classes. $<6$ - class I, low risk; 7-17 - class II, intermediate risk; and > 18 - class III, high risk

range: $8.0-36.8 \mathrm{ng} / \mathrm{ml}$ ) compared with patients with an uncomplicated course $(3.4 \mathrm{ng} / \mathrm{ml}, 2.1-4.9 \mathrm{ng} / \mathrm{ml}$; $p<0.001)$. By logistic regression, elevated $(\geq 6 \mathrm{ng} / \mathrm{ml})$ $\mathrm{H}$-FABP was associated with a 36.6-fold increase in the death or complication risk. The combination of H-FABP with tachycardia was a particularly useful prognostic indicator. H-FABP also predicted long-term mortality over 499 (interquartile range: 204 to 1,166) days (hazard ratio: $3.6 ; 95 \%$ confidence interval: $1.6-8.2 ; p=0.003)[24,25]$.

Sanchez et al. devised a simple score based on the clinical parameters, echocardiographic finding and cardiac biomarkers to risk stratify patients according to risk of adverse outcomes [26]. Echocardiography, BNP, and cardiac troponins were obtained on admission of 570 patients with an acute $\mathrm{PE}$, and a risk score stratification for 30-day adverse events was developed (Table V).

\section{Early diagnosis}

Early diagnosis is the key in the management of $P E$. The interval from the onset of symptoms to death is relatively short. In patients with massive PE, 50\% die within 30 min, $70 \%$ die within $1 \mathrm{~h}$, and more than $85 \%$ die within $6 \mathrm{~h}$ of the onset of symptoms [27]. The PE is frequently undiscovered until autopsy [28].

Massive PE should be suspected in patient with unexplained hypotension accompanied by an elevated central venous pressure (or neck vein distension), which is not otherwise explained by acute myocardial infarction, tension pneumothorax, pericardial tamponade, or a new arrhythmia. Even though pulmonary angiography and spiral computed tomography (CT) angiography are diagnostic studies of choices, bedside transthoracic echocardiography (TTE) is a useful tool in hemodynamically unstable patients. It is not only used for increasing the likelihood of PE diagnosis by showing RV dysfunction and dilation but can also exclude other differential diagnoses like pericardial tamponade, cardiogenic shock, and aortic dissection. Transthoracic echocardiography is also helpful to rule out patent foramen ovale (PFO) and the risk of paradoxical systemic embolism. In patients who can be stabilized with fluids, pressors, or mechanical ventilation; a spiral chest CT angiography can be done for confirmation of pulmonary embolism.

In a suspected PE, no clinical risk factor, clinical finding, or laboratory value considered alone can be used to make a diagnosis of PE, but when taken as a group, they can determine the pretest probability (PTP) of the patient having PE. For standardizing the approach to diagnosis of $\mathrm{PE}$, clinical decision rules (CDR) have been devised which take in to account the clinical presentation, laboratory values, and chest radiograph. The most commonly used CDRs are Wells criteria (Table VI) and Geneva score. The use of the CDR leads to a more systematic prediction of the pretest probability hence early initiation of treatment before the diagnostic tests are done which have been proven to decrease the 30 day mortality [29].

D dimer testing has a high sensitivity and low specificity for diagnosing PE. The use of this assay is mainly for its high negative predictive value in patients with a low PTP. ELISA is the preferred 
Table VI. Wells scores for predicting PTP of PE

\begin{tabular}{|c|c|c|c|}
\hline Wells & Score & Modified wells & Score \\
\hline Clinical signs of DVT & 3.0 & Clinical signs of DVT & 1.0 \\
\hline Recent surgery or immobilization & 1.5 & Recent surgery or immobilization & 1.0 \\
\hline Heart rate $>100$ beats $/ \mathrm{min}$ & 1.5 & Heart rate $>100$ beats $/ \mathrm{min}$ & 1.0 \\
\hline Previous VTE & 1.5 & Previous VTE & 1.0 \\
\hline Hemoptysis & 1.0 & Hemoptysis & 1.0 \\
\hline Malignancy & 1.0 & Malignancy & 1.0 \\
\hline Alternative diagnosis less likely than PE & 3.0 & Alternative diagnosis less likely than PE & 1.0 \\
\hline
\end{tabular}

method used for the assay and has been shows to be very helpful in ruling out PE in patients with low PTP with high certainty $[30,31]$.

A VQ scan can be done as the first modality for diagnosis for the patients who are allergic to dyes, in renal failure, claustrophobic, and in young women (due to risk for radiation exposure) [32]. The patients can be divided into high, indeterminate, and low probability scans. Salaun et al. showed that when used in conjunction with lower extremity compression ultrasound, VQ scan diagnosed PE in $76 \%$ of the cohort population, and only $11 \%$ needed CTPA to make a diagnosis, with a low rate of recurrent VTE in those not treated with anticoagulation [33]. The diagnostic yield of the VQ scan can be increased by selecting patients who have a normal chest radiograph and no cardiopulmonary disease [33].

In the presence of limitations for a VQ scan, CTPA should be done for the diagnosis of PE. The limitations of the modality include high radiation exposure, contrast induced nephropathy, and overdiagnosing isolated subsegmental PE, which may not need treatment [34, 35].

\section{Role of transesophageal echocardiography}

Transesophageal echocardiography (TEE) is a method that is beneficial and is gaining acceptance in the pathway of diagnosis of massive PE either pre-operatively or intra-operatively $[36,37]$. Transesophageal echocardiography makes it possible to diagnose PE by direct visualization of a thrombus rather than by relying on indirect signs, such as RV enlargement and hypokinesis. Transesophageal echocardiography assesses the extent of thromboembolism as well as its surgical accessibility [38]. Pruszczyk et al. showed that TEE has a $80.5 \%$ sensitivity anda $97.2 \%$ specificity in demonstrating blood clots in the main or lobar pulmonary arteries in patients who had suspected PE and RV overload on initial transthoracic echocardiography [39].
Transesophageal echocardiography can identify extrapulmonary thromboemboli in the inferior or superior vena cava, the right atrium, or the right ventricle. Funakoshi et al. demonstrated in a series of 50 consecutive patients undergoing pulmonary embolectomy that TEE reveals extrapulmonary thromboemboli within the previously described locations in $26 \%$ of all patients [40]. If not surgically removed, such extrapulmonary thromboemboli can become the source of recurrent PE. Therefore, intraoperative TEE should be considered in patients undergoing pulmonary embolectomy, even in the presence of acute hemodynamic instability.

\section{Initial stabilization}

Acute circulatory failure is the leading cause of death in patients with massive PE and is primarily caused by a sudden obstruction to RV outflow [41]. The essential pathophysiology of shock following massive PE is well illustrated in Figure 1.

Acute obstruction to RV outflow by massive PE leads to RV pressure and volume overload and ultimately results in left ventricular (LV) failure from 2 different mechanisms. First, the RV outflow obstruction results in reduced LV preload. Second, increased RV end-diastolic pressure (RVEDP) impairs LV diastolic filling due to bulging of the interventricular septum into the LV cavity, also known as diastolic ventricular interdependence [42]. Both of these factors ultimately contribute to a low cardiac output (CO) and systemic hypotension. Right ventricular coronary perfusion pressure (RV CPP) is the difference between mean arterial pressure (MAP) and RVEDP. Systemic hypotension as well as elevated RV end-diastolic pressure may reduce RV coronary perfusion pressure and myocardial blood flow resulting in $\mathrm{RV}$ ischemia $[43,44]$. This has been confirmed in patients with acute massive $P E$ by an increase in creatine kinase $M B$ isoenzyme and troponins, or even RV infarction at autopsy despite normal coronary arteries $[45,46]$.

As a significant number of deaths occurs within a few hours after the onset of symptoms, initial 


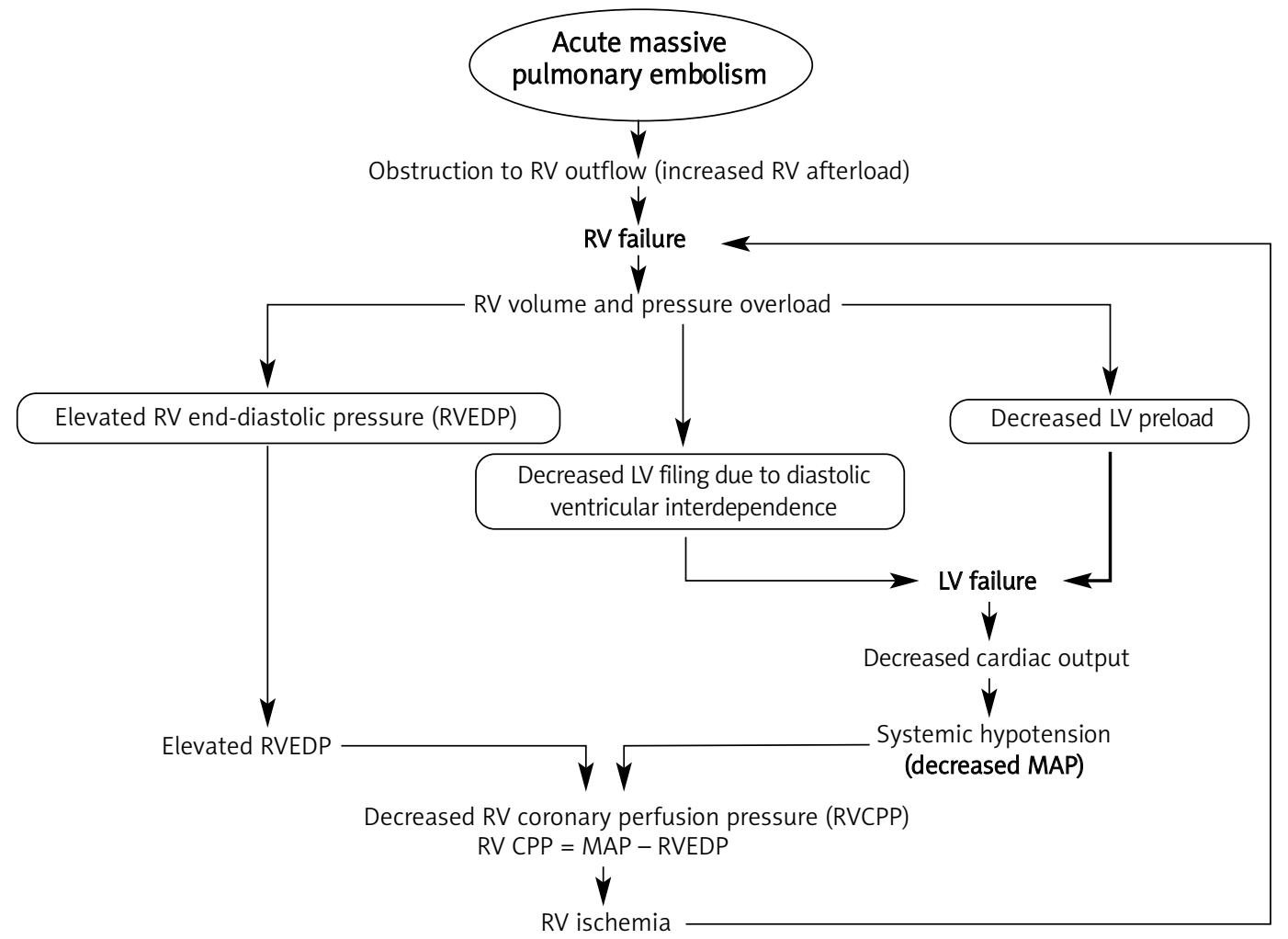

Figure 1. Pathophysiology of cardiovascular collapse following massive pulmonary embolism

$R V$ - right ventricle, $L V$ - left ventricle, RVEDP - right ventricular end-diastolic pressure, MAP - mean arterial pressure, $R V C P P$ - right ventricular coronary perfusion pressure

supportive treatment has a major role in the management of patients with massive PE. Unfortunately, most of the knowledge regarding effectiveness of this initial stabilization treatment is based on experimental studies.

\section{Volume expansion}

Traditionally, volume expansion with 1 to 2 I of crystalloid is the initial treatment for hypotension in patients with undifferentiated shock. Mercat et al. observed an increase in cardiac index after a $500 \mathrm{ml}$ dextran 40 infusion in patients with acute PE and low cardiac index, but all 13 patients were normotensive in that study [47].

However, in hypotensive patients with moderate to severe RV dysfunction; the aggressive fluid administration may lead to further increased RVEDP as well as decreased RV coronary perfusion pressure, ultimately resulting in RV ischemia and further deterioration in RV function [48]. Many experimental studies have confirmed this theory [49-51].

Therefore, when measured right-sided pressures such as central venous pressure are high $(>12$ $15 \mathrm{~mm} \mathrm{Hg}$ ), or when there is documented severe RV dysfunction, fluids should be used with caution, and early consideration should be given to vasopressor therapy $[44,52]$.

\section{Vasopresors and inotropes}

While awaiting primary therapy (embolectomy or thrombolysis), supportive use of vasopressors and inotropes is often necessary. The ideal agent should enhance RV function through positive inotropic effects and increase MAP through peripheral vasoconstriction without significantly increasing pulmonary vascular resistance [52].

Norepinephrine, epinephrine, and high-dose dopamine have demonstrated favorable hemodynamic effects in the setting of acute PE and circulatory failure $[44,52]$. Norepinephrine can be considered a more preferable agent for the following reasons. First, $\alpha$-mediated vasoconstriction leads to increase in MAP which in turn increases RV CPP. Second, $\beta 1$-mediated inotropic effect may improve RV function. Third, it has minimal effect on pulmonary vascular pressures [43].

The inotropes dobutamine and milrinone enhance RV function and cardiac output and reduce pulmonary vascular resistance. However, these agents have a potent vasodilatory property and can lead to significant systemic hypotension, especially in already hypotensive patients [52, 53]. Inotropes can be used successfully in conjunction with vasopressors to minimize their systemic vasodilatory effects [52]. 
The hypotensive patient with decreased cardiac output should be first started on vasopressors, and inotropes can be added later if cardiac output remains low. In contrast, inotropes can be started first in normotensive patients with evidence of decreased cardiac output, and vasopressors can be added if a hypotensive response to inotropes develops [52].

\section{Vasodilators}

The goal of vasodilator use in RV failure due to massive PE is to improve right-sided cardiac output by reducing $\mathrm{RV}$ afterload [44, 45]. Conventional vasodilators such as nitroglycerin, nitroprusside, and hydralazine have a vasodilatory effect on the pulmonary vasculature that leads to reduction in PVR and RV afterload. However, they have a more profound vasodilatory effect on the systemic vasculature, ultimately leading to a higher risk of decreasing SVR and worsening RV ischemia [45].

Pulmonary vasodilators such as prostacyclin (epoprostenol and prostaglandin 12) and inhaled nitric oxide (NO) are shown to have a promising role in management of RV failure due to various etiologies $[53,55]$. There have been some case reports with the use of these agents in the management of massive PE to decrease PVR and increase CO [55, 56]. A major concern about use of prostacyclin is the possible risk of worsening ventilation-perfusion mismatch or increasing pulmonary capillary wedge pressure in patients with concurrent LV dysfunction [53]. Both prostaglandin E1 and prostacyclin may cause systemic hypotension [57].

Inhaled NO may be useful in managing RV failure and decreasing pulmonary vascular resistance without reducing systemic pressures. In addition, Inhaled NO appears to improve the ventilation-perfusion mismatch by increasing perfusion only to areas that are well-ventilated. Inhaled NO may also enhance the efficacy of inotropic therapy by reducing the afterload and increasing right-sided cardiac output [58]. The effect of nitric oxide on RV function has been evaluated in patients with pulmonary hypertension and echocardiographically diagnosed acute RV failure due to various etiologies including not only PE but also acute respiratory distress syndrome, pulmonary hypertension, chronic obstruc- tive pulmonary disease, and obstructive sleep apnea $[59,60]$. Inhaled NO has been shown to reduce pulmonary vascular resistance and increase RV ejection fraction.

If cardiac output remains low despite vasopressors and inotropes, a pulmonary vasodilator trial with inhaled nitric oxide may be beneficial when pulmonary hypertension is present [52].

\section{Medical management}

The medical management of pulmonary embolism consists of anticoagulation and thrombolysis. The current established regimen for management of pulmonary embolism is illustrated in Figure 2.

\section{Anticoagulation}

When acute PE is considered likely, anticoagulation with heparin should be begun while pursuing the diagnostic workup [61]. In an unstable patient with suspected submassive to massive pulmonary embolism, it is reasonable to start anticoagulation immediately and preferably with shortacting, intravenously administered unfractionated heparin (UFH). The rapid reversibility of intravenous UFH is important for these patients who may require thrombolysis or surgical embolectomy.

Short-acting, intravenously administered UFH should be initiated with a bolus of $80 \mathrm{U} / \mathrm{kg}$ followed by a continuous infusion of $18 \mathrm{U} / \mathrm{kg}$ per hour. This weight-based heparin protocol has been shown to reach the therapeutic range more quickly and reliably than the standard normogram [62]. It is reasonable to aim for a higher partial thromboplastin time (PTT) range to avoid a subtherapeutic PTT initially.

For stable patients with $\mathrm{PE}$, there is increasing interest in using weight-based dosing of low-molecular-weight heparin (LMWH) instead of UFH. Lowmolecular-weight heparin has proved to be as effective as or superior to intravenous UFH infusion [63-65]. The synthetic pentasaccharide, fondaparinux, has also been shown to be not inferior to UFH for initial anticoagulation in the management of PE [66].

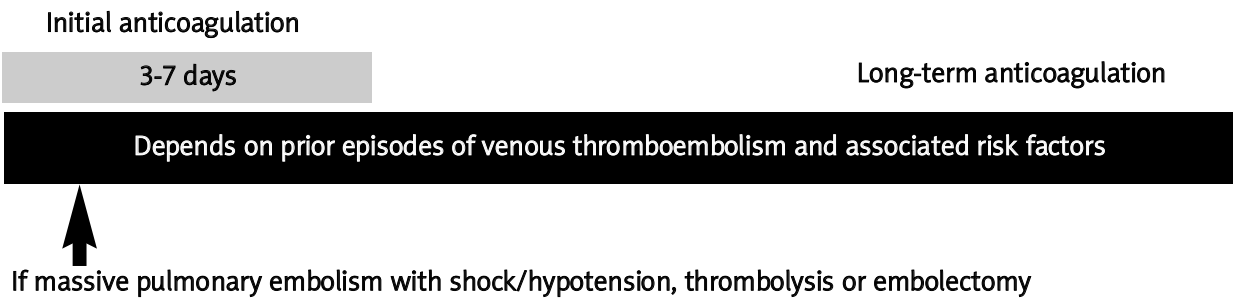

Figure 2. Current established regimen for management of pulmonary embolism 
The American College of Chest Physicians 2008 evidence-based guidelines on antithrombotic therapy for venous thromboembolism recommends use of UFH or LMWH or fondaparinux for initial anticoagulation following PE [61]. When heparin-induced thrombocytopenia (HIT) complicates management, the intravenous direct thrombin inhibitors argatroban [67] or lepirudin [68] should be used.

For long-term anticoagulation, the American College of Chest Physicians 2008 evidence-based guidelines on antithrombotic therapy for venous thromboembolism (VTE) [61] recommends:

1. Using warfarin together with initial anticoagulation with UFH or LMWH or fondaparinux (grade 1C)

2. The initial anticoagulation with UFH or LMWH or fondaparinux should be continued for at least 5 days and until the international normalized ratio (INR) is $>2.0$ for at least $24 \mathrm{~h}$ (grade $1 \mathrm{C}$ ).

3. In patients who receive long-term anticoagulant treatment, the risk-benefit ratio of continuing such treatment should be reassessed in the individual patient at periodic intervals (grade 1C).

4. The dose of warfarin should be adjusted to maintain a target INR of 2.5 (INR range: 2.0-3.0) for all treatment durations (grade $1 \mathrm{~A}$ ).

5. The duration of long-term anticoagulation depends on prior episodes of VTE and presence of associated risk factors, which are shown in Table VII.

The preferred agent for long-term anticoagulation is warfarin with one exception. The use of L Low-molecular-weight heparin is recommended for long-term anticoagulation rather than warfarin in patients with VTE associated with cancer $[61,69]$. This strategy has been shown to reduce the risk of recurrent VTE in patients with cancer $[70,71]$ as well as improve mortality in a subgroup of cancer patients [71]. Otherwise, monotherapy with LMWH is also suitable for patients either intolerant of warfarin or unable to maintain therapeutic levels of warfarin.

\section{Fibrinolytic therapy for massive pulmonary embolism}

Thrombolytic therapy causes rapid lysis of clot and more rapid improvement in RV hemodynamics. Thrombolytic therapy is recommended as standard, first-line treatment in patients with massive PE, unless contraindicated [61]. As noted earlier, the majority of patients with acute PE and cardiogenic shock die before diagnosis or treatment.

Two meta-analyses included 9 trials which compared different thrombolytics with heparin $[72,73]$. Many of those trials excluded patients with hemodynamic compromise. In an overview of the 5 randomized controlled trials that included patients with massive PE, thrombolytic therapy has been shown to reduce the risk of death or recurrent PE by $55 \%$ [74]. Only one trial of 8 patients studied patients with cardiogenic shock due to acute PE and showed that the 4 patients treated with streptokinase survived while the 4 patients treated with heparin alone died [75].

\section{Fibrinolytic therapy for submassive pulmonary embolism}

The role of thrombolytic therapy for submassive PE is controversial $[76,77]$. There are 2 studies which investigated patients with submassive PE (normotensive patients diagnosed with PE with evidence of RV dysfunction on echocardiography) [78, 79].

Hamel et al. compared 64 patients treated with thrombolytics with 64 patients treated with heparin which were matched on RV/LV diastolic diameter ratio [78]. In this retrospective study, the thrombolytic group had a higher improvement in perfusion lung scans than the heparin group. However, the in-hospital mortality was $6.25 \%$ in the thrombolytic arm and $0.0 \%$ in the heparin group. The

Table VII. Duration of use of long-term anticoagulation (adapted from [49])

\begin{tabular}{|c|c|c|}
\hline Variable & Recommended duration of treatment & Level of recommendation \\
\hline $\begin{array}{l}\text { An episode of VTE secondary to } \\
\text { a transient risk factor }\end{array}$ & $\begin{array}{l}\text { Continue anticoagulation with warfarin for } \\
3 \text { months }\end{array}$ & Grade $1 \mathrm{~A}$ \\
\hline \multirow[t]{2}{*}{$\begin{array}{l}\text { An episode of VTE associated with } \\
\text { concurrent cancer }\end{array}$} & $\begin{array}{l}\text { Continue anticoagulation with LWMH for } \\
\text { 3-6 months }\end{array}$ & Grade $1 \mathrm{~A}$ \\
\hline & $\begin{array}{l}\text { Continue subsequent anticoagulation with } \\
\text { warfarin or LMWH indefinitely or until cancer } \\
\text { is resolved }\end{array}$ & Grade $1 \mathrm{C}$ \\
\hline First episode of unprovoked & Continue anticoagulation with VKA for 3 months & Grade $1 \mathrm{~A}$ \\
\hline VTE & $\begin{array}{l}\text { After first } 3 \text { months, continue anticoagulation } \\
\text { with warfarin if risk-benefit ratio is favorable: } \\
\text { - Low risk for bleeding } \\
\text { - Reliable follow-up for INR monitoring }\end{array}$ & Grade $1 \mathrm{~A}$ \\
\hline Second episode of unprovoked VTE & Indefinite & Grade $1 \mathrm{C}$ \\
\hline
\end{tabular}


rates of recurrent PE were the same in both groups. The incidence of intracranial bleeding was $4.7 \%$ in the thrombolytic group.

Konstantinides et al. performed a randomized controlled trial of 256 patients with submassive PE [79]. The in-hospital mortality rates were similar in both the heparin plus alteplase group and heparin plus placebo groups (3.4\% vs. $2.2 \%$ respectively). The rate of treatment escalation (which was defined as catecholamine infusion, secondary thrombolysis, endotracheal intubation, cardiopulmonary resuscitation, or emergency surgical embolectomy or thrombus fragmentation by catheter) was higher in the heparin plus placebo group than in the heparin plus alteplase group ( $24.6 \%$ vs. $10.2 \%$ respectively). No fatal bleeding or cerebral bleeding occurred in patients receiving heparin plus alteplase. Despite the significant higher risk of adverse clinical outcomes in patients with submassive PE, most studies have failed to show a significant mortality benefit after thrombolytics in this subgroup of patients.

For proper evaluation of thrombolytic therapy in the treatment of submassive PE, the following questions must be answered: 1) what is the clinical importance of early resolution of PE obstruction by thrombolytics?; 2) are thrombolytics effective in prevention of recurrent PE?; 3) what is the rate of major bleeding complications including intracranial hemorrhage associated with use of thrombolytics?; and 4) what are the potential long-term benefits after use of thrombolytics in submassive PE? These questions need to be answered appropriately by a large-scale clinical trial [80].

Few of the above questions have been attempted to be answered. Kline et al. conducted a study of 200 patients with massive PE with echocardiography performed at the time of diagnosis and after 6 months [81]. The change in the estimated pulmonary artery pressure was measured. Twenty-seven percent of the patient receiving heparin alone had an increase in estimated pulmonary artery pressure, and $50 \%$ of them were symptomatic [81].

The median decrease in the estimated pulmonary artery pressure was $22 \mathrm{~mm} \mathrm{Hg}$ in patients treated with tPA and heparin as compared with $2 \mathrm{~mm} \mathrm{Hg}$ in those treated with heparin alone [81]. There was no increase in the estimated pulmonary artery pressure in any of the patients receiving tPA [81].

The Pulmonary Embolism International Thrombolysis Trial (PEITHO) is a large randomized controlled trial started in 2007 with results expected in 2013. Approximately 1000 patients from over 12 countries will be enrolled to evaluate a primary clinical end point of all-cause mortality or hemodynamic collapse within 7 days in patients treated with the fibrinolytic agent tenecteplase plus heparin versus heparin alone.

\section{How thrombolytics should be initiated}

As soon as the decision is made to administer thrombolytics, heparin should be discontinued. No coagulation test is necessary during thrombolysis as the doses of thrombolytic agents are either fixed or weight-based. The Food and Drug Administration (FDA) approved the thrombolytics regimens shown in Table VIII. The FDA approved dose of recombinant tissue-type plasminogen activator (rt-PA) is $100 \mathrm{mg}$ given over over $2 \mathrm{~h}$. One study showed similar efficacy and perhaps better safety (less bleeding tendency) of the $50 \mathrm{mg} / 2 \mathrm{~h}$ rt-PA regimen compared with the standard $100 \mathrm{mg} / 2 \mathrm{~h}$ rt-PA regimen in patients with acute PE [82].

At conclusion of the infusion of thrombolytics, an activated partial thromboplastin time (aPTT) should be obtained. If the aPTT is $<80 \mathrm{~s}$, intravenous heparin should be started as a continuous infusion without a bolus. If the aPTT is $>80 \mathrm{~s}$ after thrombolysis, heparin should be withheld, the aPTT rechecked in $4 \mathrm{~h}$, and heparin given without a bolus after the APTT is $<80 \mathrm{~s}$.

\section{Surgical management}

In the Management Strategies and Prognosis in Patients with Pulmonary Embolism (MAPPET) registry, 193 (40\%) of the 478 patients who received fibrinolysis had at least 1 relative contraindication [12]. In ICOPER, among 304 patients who received fibrinolysis, $21.7 \%$ had major bleeding complications, and $3 \%$ had intracranial bleeding [7]. These findings led to development of pulmonary embolectomy. Pulmonary embolectomy can be performed using catheters or surgically. It should be considered in patients with acute, massive PE when either thrombolysis is contraindicated or there is a lack of response to intensive medical treatment and thrombolysis.

\section{Surgical embolectomy}

The surgical technique consists of median sternotomy, with rapid cannulation of the ascending

Table VIII. Food and Drug Administration approved thrombolytic regimens for pulmonary embolism

\begin{tabular}{|ll|}
\hline Thrombolytic agents & Thrombolytic regimens \\
\hline Streptokinase & $250,000 \mathrm{IU}$ as a loading dose over $30 \mathrm{~min}$ followed by $100,000 \mathrm{IU} / \mathrm{h}$ for $24 \mathrm{~h}$ \\
\hline Urokinase & $4,400 \mathrm{IU} / \mathrm{kg}$ as a loading dose over 10 min followed by $4,400 \mathrm{IU} / \mathrm{kg} / \mathrm{h}$ for 12 to $24 \mathrm{~h}$ \\
\hline rt-PA (alteplase) & $100 \mathrm{mg}$ as a continuous intravenous infusion over $2 \mathrm{~h}$ \\
\hline
\end{tabular}


aorta and right atrium and institution of normothermic cardiopulmonary bypass. Aortic cross clamping is avoided. The emboli are removed via a longitudinal incision in the main pulmonary artery, using a common bile duct forceps. A standard sucker is used to extract the most distal clots.

In a prospective study comparing surgical versus medical treatment in patients with massive PE, the medical group had an increased mortality and a higher recurrence of PE [83]. This was confirmed by a more recent prospective study showing the superiority of surgery over thrombolysis after one failed thrombolysis for massive PE [84]. In 64 patients with RV dilation due to acute PE, in-hospital mortality occurred in 2 of 18 hemodynamically unstable patients (11\%) who underwent pulmonary embolectomy, in 2 of 6 hemodynamically stable patients (33\%) treated with thrombolytic therapy plus intravenous heparin, and in 17 of 40 hemodynamically stable patients (43\%) treated with intravenous heparin $(p<0.025$ comparing pulmonary embolectomy with no pulmonary embolectomy) [85].

Depending on the series, the overall mortality rate after open surgical pulmonary embolectomy varies from $16 \%$ to $46 \%$ with a mean mortality rate of $26 \%$ [86-90]. The high mortality rate is due to the fact that most patients who undergo surgical embolectomy are hemodynamically compromised and arrive at the operating room in cardiac arrest with cardiopulmonary resuscitation (CPR) in progress, or else they have had CPR performed beforehand.

Data suggest that preoperative hemodynamic status is the most important prognostic indicator of postoperative outcome after surgical pulmonary embolectomy, and cardiac arrest and CPR are independent factors predictive of postoperative death [91]. Surgical embolectomy in hemodynamically stable patients as the primary treatment shows excellent long-term results [92].

During the preoperative or intraoperative period, TEE is extremely reliable for diagnosis by evaluating RV function and localizing thrombi within the pulmonary arterial tree. Intra-operative TEE also helps to look for extrapulmonary thrombi (i.e., thrombi in the right atrium, RV, or inferior vena cava). In a series of 50 patients with PE, intraoperative TEE detected extrapulmonary thrombi in $26 \%$, which altered the surgical management [40]. Some experts feel that pulmonary embolectomy should be combined with inferior vena cava filter insertion [93-95].

\section{Catheter embolectomy}

Surgical embolectomy is mainly limited to large medical centers as it requires an experienced surgeon and cardiopulmonary bypass capability. The alternative to open surgical embolectomy is percutaneous catheter embolectomy.

Various intrapulmonary arterial techniques have been utilized to reduce the embolic burden in patients with PE. Major techniques involved are fragmentation of blood clot and aspiration. Fragmentation can be done using either a rheolytic catheter (injecting pressurized saline through the catheter's distal tip, which macerates the emboli) or a rotational catheter (catheter with high-speed rotational coil). Some also recommend use of intrapulmonary administration of fibrinolytics to accelerate clot lysis and improve pulmonary circulation.

Complications of catheter embolectomy include perforation or dissection of major pulmonary arterial branches, pericardial tamponade from damage to the RV myocardium, arrhythmias from catheter passage through the right heart, mechanical hemolysis, and pseudoaneurysm [96].

Case series using these techniques are small with promising outcomes [97-100]. None of the techniques has been compared with other forms of therapy. Larger studies are needed to determine which, if any, catheter technique is most effective compared to alternative treatment modalities. At the same time, catheter embolectomy might not retrieve all of the clot material putting patients at higher risk to develop chronic pulmonary hypertension.

\section{Role of inferior vena cava filter}

The role of the inferior vena cava (IVC) filter in management of acute PE is mainly in patients with contraindication of fibrinolysis and embolectomy and in prevention of the recurrent PE. If no deep venous thrombosis is present at the time of surgery, and there are no contraindications for anticoagulation, IVC filter insertion is controversial. The use of the IVC filter has not been associated with lowering of long-term mortality and has been associated with an increase in the risk of deep vein thrombosis [101]. With the newer retrievable filters, one may consider removal if venography after 10-14 days reveals no distal thrombi.

\section{References}

1. Torbicki A, van Beek EJR, Charbonnier B, et al.Guidelines on diagnosis and management of acute pulmonary embolism. Task Force on Pulmonary Embolism - European Society of Cardiology. Eur Heart J 2000; 21: 1301-36.

2. Kasper W, Konstantinides S, Geibel A, et al. Management strategies and determinants of outcome in acute major pulmonary embolism: results of a multicenter registry. J Am Coll Cardiol 1997; 30: 1165-71.

3. Grifoni, S, Olivotto, I, Cecchini, P, et al. Short-term clinical outcome of patients with acute pulmonary embolism, normal blood pressure, and echocardiographic right ventricular dysfunction. Circulation 2000; 101: 2817-22. 
4. Kasper, W, Konstantinides, S, Geibel, A, et al. Prognostic significance of right ventricular afterload stress detected by echocardiography in patients with clinically suspected pulmonary embolism. Heart 1997; 77: 346-9.

5. Ribeiro A, Lindmarker P, Juhlin-Dannfelt A, et al. Doppler echocardiography in pulmonary embolism: right ventricular dysfunction as a predictor of mortality rate. Am Heart J 1997; 134: 479-87.

6. Wolfe MW, Lee RT, Feldstein ML, et al. Prognostic significance of right ventricular hypokinesis and perfusion lung scan defects in pulmonary embolism. Am Heart J 1994; 127: 1371-5.

7. Goldhaber SZ, Visani L, DeRosa M. Acute pulmonary embolism: clinical outcomes in the International Cooperative Pulmonary Embolism Registry (ICOPER). Lancet 1999; 353: 1386-9.

8. Kasper W, Konstantinides S, Geibel A, et al. Management strategies and determinates of outcome in acute major pulmonary embolism: results of a multi-center registry. J Am Coll Cardiol 1997; 30: 1165-71.

9. Piazza G, Goldhaber SZ. Acute pulmonary embolism, part II: treatment and prophylaxis. 2006; 114: e42-7.

10. McConnell MV, Solomon SD, Rayan ME, et al. Regional right ventricular dysfunction detected by echocardiography in acute pulmonary embolism. Am J Cardiol 1996; 78: 469-73.

11. Vanni S, Polidori G, Vergara R, et al. Prognostic value of ECG among patients with acute pulmonary embolism and normal blood pressure. Am J Med 2009; 122: 257-64

12. Stein PD, Dalen JE, Mclntyre KM, et al. The electrocardiogram in acute pulmonary embolism. Prog Cardiovasc Dis 1975; 17: 247-57.

13. Stein PD, Terrin ML, Hales CA, et al. Clinical, laboratory, roentgenographic, and electrocardiographic findings in patients with acute pulmonary embolism and no pre-existing cardiac or pulmonary disease. Chest 1991; 3: 598-603.

14. Ferrari E, Imbert A, Chevalier T, et al. The ECG in pulmonary embolism. Predictive value of negative $T$ waves in precordial leads - 80 case reports. Chest 1997; 111: 537-43.

15. Iles S, Le Heron CJ, Davies G, et al. ECG score predicts those with the greatest percentage of perfusion defects due to acute pulmonary thromboembolic disease. Chest 2004; 125: 1651-6.

16. Daniel KR, Courtney DM, Kline JA. Assessment of cardiac stress from massive pulmonary embolism with 12-lead ECG. Chest 2001; 120: 474-81.

17. Giannitsis E, Muller-Bardorff M, Kurowski V. Independent prognostic value of cardiac troponin $\mathrm{T}$ in patients with confirmed pulmonary embolism. Circulation 2000; 102: 211-7.

18. Sohne $M$, ten Wolde $M$, Buller H. Biomarkers in pulmonary embolism. Current Opinion in Cardiology 2004; 19: 558-62.

19. Konstantinides S, Geibel A, Olschewski $M$, et al. Importance of cardiac troponins I and $\mathrm{T}$ in risk stratification of patients with acute pulmonary embolism. Circulation 2002; 106: 1263-8.

20. ten Wolde M, Tulevski II, Mulder JWM, et al. Brain natriuretic peptide as a predictor of adverse outcome in patients with pulmonary embolism. Circulation 2003; 107: 2082-4.

21. Kucher N, Printzen G, Goldhaber SZ. Prognostic role of brain natriuretic peptide in acute pulmonary embolism. Circulation 2003; 107: 2545-7.

22. Pieralli F, Olivotto I, Vanni S, et al. Usefulness of bedside testing for brain natriuretic peptide to identify right ventricular dysfunction and outcome in normotensive patients with acute pulmonary embolism. Am J Cardiol 2006; 97: 1386-90.

23. Kostrubiec M, Pruszczyk P, Bochowicz A, et al. Biomarkerbased risk assessment model in acute pulmonary embolism. Eur Heart J 2005; 26: 2166-72.

24. Puls M, Dellas C, Lankeit M, et al. Heart-type fatty acidbinding protein permits early risk stratification of pulmonary embolism. Eur Heart J 2007; 28: 224-9.

25. Dellas C, Puls M, Lankeit $M$, et al. Elevated heart-type fatty acid binding protein levels on admission predict adverse outcome in normotensive patients with acute pulmonary embolism. J Am Coll Cardiol 2010; 55: 2150-7.

26. Sanchez O, Trinquart L, Caille V, et al. Prognostic factors for pulmonary embolism: the PREP study, a prospective multicenter cohort study. Am J Respir Crit Care Med 2010; 181: 168-73.

27. Stulz P, Schlapfer R, Feer R, et al. Decision making in the surgical treatment of massive pulmonary embolism. Eur J Cardiothorac Surg 1994; 8: 188-93.

28. Bergqvist D, Lindblad B. A 30-year survey of pulmonary embolism verified at autopsy: an analysis of 1274 surgical patients. Br J Surg 1985; 72: 105.

29. Smith SB, Geske JB, Maguire JM, et al. Early anticoagulation is associated with reduced mortality for acute pulmonary embolism. Chest 2010; 137: 1382-90.

30. Stein PD, Hull RD, Patel KC, et al. D-dimer for the exclusion of acute venous thrombosis and pulmonary embolism: a systematic review. Ann Intern Med 2004; 140: 589-602.

31. Di Nisio M, Squizzato A, Rutjes AW, et al. Diagnostic accuracy of D-dimer test for exclusion of venous thromboembolism: a systematic review. J Thromb Haemost 2001; 5: 296-304.

32. Anderson DR, Barnes DC. Computerized tomographic pulmonary angiography versus ventilation perfusion lung scanning for the diagnosis of pulmonary embolism. Curr Opin Pulm Med 2009; 15: 425-9.

33. Salaun PY, Couturaud F, LE Duc-Pennec A, et al. Noninvasive diagnosis of pulmonary embolism. Chest 2011; 139: $1294-8$.

34. Eyer BA, Goodman LR, Washington L. Clinicians response to radiologists report of isolated subsegmental pulmonary embolism using MDCT. AJR Am J Roentgenol 2005; 184: 623-8.

35. Le Gal G, Righini M, Parent F, et al. Diagnosis and management of subsegmental pulmonary embolism. J Thromb Haemost 2006; 4: 724-31.

36. Thys DM, Abel M, Bollen BA, et al. Practice guidelines for perioperative transesophageal echocardiography. A report by the American Society of Anesthesiologists and the Society of Cardiovascular Anesthesiologists Task Force on Transesophageal Echocardiography. Anesthesiology 1996; 84: 986-1006.

37. Cahalan MK, Abel M, Goldman M, et al. American Society of Echocardiography and Society of Cardiovascular Anesthesiologists task force guidelines for training in perioperative echocardiography. Anesth Analg 2002; 94: 1384-8.

38. Goldhaber SZ. Echocardiography in the management of pulmonary embolism. Ann Intern Med 2002; 136: 691-700.

39. Pruszczyk P, Torbicki A, Kuch-Wocial A, et al. Diagnostic value of transoesophageal echocardiography in suspected haemodynamically significant pulmonary embolism. Heart 2001; 85: 628-34

40. Rosenberger P, Shernan SK, Mihaljevic T, et al. Transesophageal echocardiography for detecting extra- 
pulmonary thrombi during pulmonary embolectomy. Ann Thorac Surg 2004; 78: 862-6.

41. Mclntyre KM, Sasahara AA. Determinants of right ventricular function and hemodynamics after pulmonary embolism. Chest 1974; 65: 534-43.

42. Belenkie I, Dani R, Smith ER, Tyberg JV. Ventricular interaction during experimental acute pulmonary embolism. Circulation 1988; 78: 761-8.

43. Wood KE. Major pulmonary embolism - review of a pathophysiologic approach to the golden hour of hemodynamically significant pulmonary embolism. Chest 2002; 121: 877-905.

44. Layish DT, Tapson VF. Pharmacologic hemodynamic support in massive pulmonary embolism. Chest 1997; 111: 218-24.

45. Adams JE, Siegel BA, Goldstein ML, et al. Elevation of CKMB following pulmonary embolism. Chest 1992; 101: 1203-6.

46. Ramirez-Rivera A, Gutierrez-Fajardo P, Jerjes-Sanchez C, et al. Acute right myocardial infarction without significant obstructive coronary lesions secondary to massive pulmonary embolism. Chest 1993; 104: 80S.

47. Mercat A, Diehl JL, Meyer G, et al. Hemodynamic effects of fluid loading in acute massive pulmonary embolism. Crit Care Med 1999; 27: 540-4.

48. Ducas J, Prewitt RM. Pathophysiology and therapy of right ventricular dysfunction due to pulmonary embolism. Cardiovasc Clin 1987; 17: 191-202.

49. Molloy DW, Lee KY, Girling L, et al. Treatment of shock in a canine model of pulmonary embolism. Am Rev Respir Dis 1984; 130: 870-4.

50. Belenkie I, Dani R, Smith ER, et al. Effects of volume loading during experimental acute pulmonary embolism. Circulation 1989; 80; 178-88.

51. Ghignoue M, Girling L, Prewitt RM. Volume expansion vs. norepinephrine in treatment of low cardiac output complicating an acute increase in right ventricular afterload in dogs. Anesthesiology 1984; 60: 132-5.

52. Piazza G, Goldhaber SZ. The acutely decompensated right ventricle. Pathways for diagnosis and management. Chest 2005; 128: 1836-52.

53. Lualdi JC, Goldhaber SZ. Right ventricular dysfunction after acute pulmonary embolism: pathophysiologic factors, detection, and therapeutic implications. Am Heart 1995; 130: 1276-82.

54. Goldstein JA. Pathophysiology and management of right heart ischemia. J Am Coll Cardiol 2002; 40: 841-53.

55. Capellier G, Jacques T, Balvay P, et al. Inhaled nitric oxide in patients with pulmonary embolism. Intensive Care Med 1997; 23: 1089-92.

56. Webb SA, Stott S, van Heerden PV. The use of inhaled aerosolized prostacyclin (IAP) in the treatment of pulmonary hypertension secondary to pulmonary embolism. Intensive Care Med 1996; 22: 353-5.

57. Stobierska-Dzierzek B, Awad H, Michler RE. The evolving management of acute right-sided heart failure in cardiac transplant recipients. J Am Coll Cardiol 2001; 38: 923-31.

58. McNeil K, Dunning J, Morrell NW. The pulmonary physician in critical care: 13 . The pulmonary circulation and right ventricular failure in the ITU. Thorax 2003; 58: 157-62.

59. Fierobe L, Brunet F, Dhainaut JF, et al. Effect of inhaled nitric oxide on right ventricular function in adult respiratory distress syndrome. Am J Respir Crit Care Med 1995; 151: 1414-9.

60. Bhorade S, Christenson J, O'Connor M, et al. Response to inhaled nitric oxide in patients with acute right heart syndrome. Am J Respir Crit Care Med 1999; 159: 571-9.
61. Kearon C, Kahn SR, Agnelli G, et al. Antithrombotic therapy for VTE: ACCP evidence-based clinical practice guidelines (8th Edition). Chest 2008; 133: 454-545.

62. Raschke R, Reilly BM, Srinivas $S$, et al. The weight based heparin dosing nomogram versus a standard care nomogram: a randomized controlled trial. Ann Intern Med 1993; 119: 874-81.

63. Meyer G, Brenot F, Pacouret G, et al. Subcutaneous LMWH versus intravenous UFH in the treatment of acute non-massive PE. Haemost 1995; 74: 1432-5.

64. The Columbus Investigators. Low molecular weight heparin in the treatment of patients with venous thromboembolism. N Engl J Med 1997; 337: 657-62.

65. Simonneau G, Sors H, Charbonnier S; THESEE study group. A comparison of LMWH with UFH for acute pulmonary embolism. N Engl J Med 1997; 337: 663-9.

66. Buller HR, Davidson BL, Decousus H, et al. Subcutaneous fondaparinux versus intravenous unfractionated heparin in the initial treatment of pulmonary embolism. N Engl J Med 2003; 349: 1695-702.

67. Lewis BE, Wallis DE, Berkowitz SD, et al. Argatroban anticoagulant therapy in patients with heparin-induced thrombocytopenia. Circulation 2001; 103: 1838-43.

68. Greinacher A, Janssens U, Berg G, et al. Lepirudin for parenteral anticoagulation in patients with heparininduced thrombocytopenia. Circulation 1999; 100: 587-93.

69. Beckman JA, Dunn K, Sasahara AA, et al. Enoxaparin monotherapy without oral anticoagulation to treat acute symptomatic PE. Thromb Haemost 2003; 89: 953-8.

70. Lee AY, Levine MN, Baker RI, et al.; CLOT investigators. Low-molecular-weight heparin versus a coumarin for the prevention of recurrent venous thromboembolism in patients with cancer. N Engl J Med 2003; 349: 146-53.

71. Hull RD, Pineo GF, Brant RF, et al.; LITE Trial Investigators. Long-term low-molecular-weight heparin versus usual care in proximal-vein thrombosis patients with cancer. Am J Med 2006; 119: 1062-72.

72. Agnelli G, Becattini C, Kirschstein T. Thrombolysis vs heparin in the treatment of pulmonary embolism: a clinical outcome-based metaanalysis. Arch Intern Med 2002; 162: 2537-41.

73. Thabut G, Thabut D, Myers RP, et al. Thrombolytic therapy of pulmonary embolism: a meta-analysis. J Am Coll Cardiol 2002; 40: 1660-7.

74. Wan S, Quinlan DJ, Agnelli G, et al. Thrombolysis compared with heparin for the initial treatment of pulmonary embolism: a meta-analysis of the randomized controlled trials. Circulation 2004; 110: 744-9.

75. Jerjes-Sanchez C, Ramirez-Rivera A, de Lourdes Garcia $M$, et al. Streptokinase and heparin versus heparin alone in massive pulmonary embolism: a randomized controlled trial. J Thromb Thrombolysis 1995; 2: 227-9.

76. Konstantinides S. Thrombolysis in submassive pulmonary embolism - Yes. J Thromb Haemost 2003; 1: 1127-9.

77. Dalen JE. Thrombolysis in submassive pulmonary embolism - No. J Thromb Haemost 2003; 1: 1130-2.

78. Hamel E, Pacouret G, Vincentelli D, et al. Thrombolysis or heparin therapy in massive pulmonary embolism with right ventricular dilation: results from a 128-patient monocenter registry. Chest 2001; 120: 120-5.

79. Konstantinides S, Geibel A, Heusel G, et al. Heparin plus alteplase compared with heparin alone in patients with submassive pulmonary embolism. N Engl J Med 2002; 347: 1143-50.

80. Goldhaber SZ. Thrombolysis in pulmonary embolism a large scale clinical trial is overdue. Circulation 2001; 140: $2876-8$ 
81. Kline JA, Steuerwald MT, Marchick MR, Hernandez-Nino J, Rose GA. Prospective evaluation of right ventricular function and functional status 6 months after acute submassive pulmonary embolism: frequency of persistent or subsequent elevation in estimated pulmonary artery pressure. Chest 2009; 136: 1202-10.

82. Wang C, Zhai Z, Yang Y, et al. Efficacy and Safety of low dose recombinant tissue-type plasminogen activator for the treatment of acute pulmonary thromboembolism. Chest 2010; 137: 254-62.

83. Gulba DC, Schmid C, Borst HG, et al. Medical compared with surgical treatment for massive pulmonary embolism. Lancet 1994; 343: 576-7.

84. Meneveau N, Seronde MF, Blonde MC, et al. Management of unsuccessful thrombolysis in acute massive pulmonary embolism. Chest 2006; 129: 1043-50.

85. Sukhija R, Aronow WS, Lee J, et al. Association of right ventricular dysfunction with in-hospital mortality in patients with acute pulmonary embolism and reduction in mortality in patients with right ventricular dysfunction by pulmonary embolectomy. Am J Cardiol 2005; 95: 695-6.

86. Clarke DB. Pulmonary embolectomy re-evaluated. Ann R Coll Surg Engl 1981; 63: 18.

87. Clarke DB, Abrams LD. Pulmonary embolectomy: a 25year experience. J Thorac Cardiovasc Surg 1986; 92: 442.

88. Yalamanchili K, Fleisher AG, Lehrman SG, et al. Open pulmonary embolectomy for treatment of major pulmonary embolism. Ann Thorac Surg 2004; 77: 819.

89. Aklog L, Williams CS, Byrne JG, et al. Acute pulmonary embolectomy: a contemporary approach. Circulation 2002; 105: 1416.

90. Dauphine C, Omari B. Pulmonary embolectomy for acute massive pulmonary embolism. Ann Thorac Surg 2005; 79: 1240.

91. Ullmann M, Hemmer W, Hannekum A. The urgent pulmonary embolectomy: mechanical resuscitation in the operating theatre determines the outcome. Thorac Cardiovasc Surg 1999; 47: 5-8.

92. Digonnet A, Moya-Plana A, Aubert S, et al. Acute pulmonary embolism: a current surgical approach. Interact CardioVasc Thorac Surg 2007; 6: 27-9.

93. Mohan CR, Hoballah JJ, Sharp WJ, et al. Comparative efficacy and complications of vena caval filters. J Vasc Surg 1995; 21: 235-46.

94. Haire WD. Vena caval filters for the prevention of pulmonary embolism. N Engl J Med 1998; 338: 463-4

95. Kucher N. Catheter embolectomy for acute pulmonary embolism. Chest 2007; 132: 657-63.

96. Brady AJB, Crake T, Oakley CM. Percutaneous catheter fragmentation and distal dispersion of proximal pulmonary embolus. Lancet 1991; 338: 1186.

97. Koning R, Cribier A, Gerber L, et al. A new treatment for severe pulmonary embolism: percutaneous rheolytic thrombectomy. Circulation 1997; 96: 2498.

98. Schmitz-Rode T, Janssens U, Duda SH, et al. Massive pulmonary embolism: percutaneous emergency treatment by pigtail rotation catheter. J Am Coll Cardiol 2000; 36: 375.

99. Kuo WT, Maurice AA, van den Bosch, et al. Catheterdirected embolectomy, fragmentation, and thrombolysis for the treatment of massive pulmonary embolism after failure of systemic thrombolysis. Chest 2008; 134: 250-4.

100. Eid-Lidt G, Gaspar J, Sandoval J, et al. Combined clot fragmentation and aspiration in patients with acute pulmonary embolism. Chest 2008; 134: 54.

101. Decousus H, Leizorovicz A, Parent F, et al. A clinical trial of vena caval filters in the prevention of pulmonary embolism in patients with proximal deep-vein thrombosis: prevention du Risque d'Embolie Pulmonaire par Interruption Cave Study Group. N Engl J Med 1998; 338: 409-15. 